Scientiæ studia, São Paulo, v. 11, n. 3, p. 491-510, 2013

\title{
: \\ Pode haver uma ciência psicanalítica sem uma metapsicologia especulativa?
}

Leopoldo Fulgencio

\begin{abstract}
范
RESUMO

Neste artigo pretendo explicitar dois sentidos básicos dados ao termo "metapsicologia" na história da psicanálise: como teoria sobre o desenvolvimento psicoafetivo do ser humano, que considera as determinações inconscientes, e como um conjunto de conceitos auxiliares, que servem como uma superestrutura especulativa teórica da psicanálise. Depois, procurarei mostrar porque é possível afirmar que Winnicott tanto rejeitou como refundou a teoria metapsicológica psicanalítica. Com tal tipo de análise, pode-se esclarecer em que sentido Winnicott usa conceitos abstratos (tais como "necessidade de ser", "tendência inata à integração", "elemento feminino puro", "solidão essencial", dentre outros), mas não conceitos especulativos, uma vez que os primeiros podem ter referentes adequados na realidade fenomênica e os segundos não. Esse tipo de distinção também torna possível recolocar a questão do lugar e da necessidade da teorização metapsicológica no desenvolvimento da psicanálise, colocando, como possibilidade, a construção de uma teoria psicanalítica como sendo uma ciência que não necessita de construções auxiliares especulativas tal como Freud propôs.
\end{abstract}

Palavras-chave • Psicanálise. Ciência. Metapsicologia. Especulação. Descrição.

É bem conhecido o enunciado de Freud, de 1937, no qual ele afirma que "sem especular nem teorizar - por pouco eu iria dizer fantasiar - metapsicologicamente, não se avança aqui um passo sequer" (Freud, 2009 [1937], p. 26). Na história da psicanálise pós-Freud encontramos diversos desenvolvimentos e modos de abordagem da metapsicologia, incluindo críticas relacionadas à sua validade e utilidade, feitas tanto por psicanalistas quanto por epistemólogos da ciência. A discussão sobre a natureza, função e validade da teorização metapsicológica mescla-se com a discussão sobre se a psicanálise pertence ou não ao campo das ciências. É nesse sentido, isto é, focando nesse tema, que espero contribuir para a discussão mais ampla da avaliação da cientificidade da psicanálise. Considerando a exposição de Vladimir Safatle no "IV Congresso Internacional de Filosofia da Psicanálise. Filosofia da Psicanálise Hoje" (Salvador, Brasil, novembro de 2011) de que há quatro grandes áreas de pesquisa em desenvolvimento (nomeadamente, a epistemologia, a história das ideias, os impactos e consequências da teoria psicanalítica na filosofia e na estética), bem como as ideias de Richard Simanke 
(cf. Simanke, 2009a, 2009b, 2010), que afirma a necessidade de analisar as concepções de ciência em geral e as possibilidades de avaliar a psicanálise, então, como uma prática cientifica, proponho abordar aqui um tema que diz respeito tanto ao desenvolvimento das pesquisas no quadro da psicanálise quanto no da filosofia e, até mesmo, no campo de intersecção entre a psicanálise e a filosofia, isso por meio de uma questão cuja resposta tem consequências profundas para o desenvolvimento da teoria e da prática psicanalítica, a saber: pode haver psicanálise sem metapsicologia?

Pode-se considerar a psicanálise como uma ciência, ou seja, como uma teoria e uma prática dedicada à resolução de problemas empíricos e clínicos, cujo conhecimento adquirido por meio de seu método de tratamento (aplicado a inúmeros pacientes) descreve e teoriza sobre alguns aspectos da própria natureza humana. Ainda que, por vezes, os campos da filosofia e da psicanálise se sobreponham e que alguns possam borrar, indevidamente, as identidades desses saberes, tomando um pelo outro, é fato admitido que Freud pretendeu dar à psicanálise um lugar no campo das ciências, diferenciando-a da filosofia, das ideologias, das artes e, principalmente, da religião. Para ele, o pior inimigo da psicanálise é a transubstanciação da teoria cientifica em uma teoria religiosa defendida em nome do pai, seja lá qual for esse pai (cf. Freud, 2004 [1933], lição 35).

Ademais, pode-se discutir que tipo de ciência é essa, se é natural ou social, ou ainda, discordar da proposta de Freud e afirmar que a psicanálise não é nem precisa ser uma ciência (cf. Assoun, 1981, 1993a, 1993b; Ellenberger, 1961, 1966; Fulgencio \& Simanke, 2005; Grünbaum, 1993, 1996; Loparic, 2001; Mezan, 2002; Monzani, 1989; Phillips, 1996; Ricoeur, 1965). Todavia, por ora não irei concentrar-me nesse âmbito mais geral da avaliação da cientificidade da psicanálise. Tomarei partido do ponto de vista que considera que a psicanálise é, ou deveria ser, uma ciência cujos fundamentos epistemológicos devem ser descritos, desenvolvidos e estabelecidos mesmo que existam enfoques teóricos diversos, por vezes incomensuráveis uns em relação aos outros. Mesmo reconhecendo a situação atual da psicanálise - uma espécie de Torre de Babel, tal como afirma Green (2005b, p. 44) referindo-se a um diálogo com Bion-considero, seguindo a perspectiva formulada por Thomas Kuhn $(1975,1977,2006)$, que a psicanálise encontra-se no período pré-paradigmático de seu desenvolvimento como ciência. Com efeito, seu amadurecimento deverá levar a um paradigma que, mostrando-se de maior valor heurístico, possibilite uma série de integrações das propostas atuais que digladiam-se pela hegemonia nesse campo. Essa integração, por sua vez, implica em inclusões e exclusões, tal como ocorre no processo de desenvolvimento das espécies em que algumas sobrevivem e se impõem, enquanto outras são levadas à extinção.

Tomando a perspectiva de Thomas Kuhn, segundo a qual a ciência seria uma prática de resolução de problemas, creio que a psicanálise pode responder de maneira 
satisfatória a tais critérios e, assim, ser reconhecida como uma prática científica. $\mathrm{Ca}$ beria esclarecer, no desenvolver dessa perspectiva, que tipo de ciência é essa, bem como quais seriam seus problemas exemplares, qual a sua teoria geral aplicável a todos os casos, qual o modelo ontológico ou metafísico que caracteriza seu modelo de homem, quais seus modelos heurísticos para formulação e resolução dos problemas em seu campo de ação e quais seus valores teóricos e práticos. Certamente encontraríamos descrições díspares desses elementos quando formulados do ponto de vista de Freud, Klein, Bion, Lacan ou Winnicott. ${ }^{1}$ Com efeito, a discussão sobre o uso e a diversidade de paradigmas na história da psicanálise tem sido feita e constitui um problema ainda em aberto (Bernardi, 1989, 2002; Fulgencio, 2007b; Loparic, 2001, 2006; Mezan, 1990, 2006). No entanto, também não é essa direção que pretendo aqui seguir, ainda que este tipo de apresentação do problema da cientificidade da psicanálise ajude a compreender o quadro e o horizonte dentro do qual farei minha análise. Procurarei, por meio de um problema específico, relativo ao tipo de teorização proposto por Freud, diferenciar o que há de especulativo do que há de descritivo em suas propostas, tendo em vista os destinos da teorização especulativa no desenvolvimento da psicanálise pós-Freud. Ou seja, irei ocupar-me com a questão da presença e da ausência da teorização metapsicológica, tomada como uma superestrutura especulativa da psicanálise, nas obras de Freud e de Winnicott.

\section{A DIVERGÊNGIA NA COMPREENSÃo DA ATITUDE DE WinNiGotT EM RELAÇÃo À METAPSIGOLOGIA}

Ao analisar o desenvolvimento da metapsicologia pós-Freud, creio ser imperativo que estejamos de acordo sobre o sentido e o referente específico a ser dado ao termo metapsicologia, sem o que não estaríamos a falar sobre as mesmas coisas. Com isso evita-se que usemos os mesmos termos para referentes diferentes e, num sentido oposto, termos diferentes para um mesmo referente. Trata-se, portanto, de respeitar uma

\footnotetext{
$1 \mathrm{O}$ uso dessa noção de paradigma no estudo da história e desenvolvimento da psicanálise contribui para que a psicanálise possa responder satisfatoriamente aos critérios usados para distinguir práticas científicas de práticas não científicas, critérios esses que ultrapassam e redescrevem os propostos por Popper (ante aos quais a psicanálise parece fracassar). Uma reação dos psicanalistas sobre o tipo de questionamento que Popper faz em relação à cientificidade da psicanálise (considerando-a muito mais próxima da astrologia do que da astronomia) está publicada em um número especial da revista Cliniques Méditerranéenes que reúne trabalhos apresentados no colóquio Démarche Scientifique, realizado na Université Louis Pasteur de Strasbourg, em maio de 1993. Como exemplo da reação crítica dos psicanalistas, cumpre mencionar a primeira frase do prefácio dessa publicação: "A denúncia popperiana da psicanálise como sendo uma ideologia é - não resta nenhum traço de dúvida - uma denúncia ideológica que não abre, na verdade, nenhum debate" (Fédida, 1994, p. 5).
} 
ética da terminologia tal como prescreve a semiótica de Peirce (1997), cuja inspiração é kantiana. Esse tipo de necessidade foi exigida pelo próprio Freud, seguindo o conselho de Kant, de maneira a evitar um diálogo de surdos-mudos, que poderia ser ilustrado pela cena de um homem ordenhando um bode enquanto o outro apara o leite com uma peneira. Diz Freud:

As duas partes capitais do delírio scherebiano, a transformação em mulher e a relação privilegiada com Deus, são conectadas no seu sistema por meio de sua posição feminina em relação a Deus. Será inevitável para nós a tarefa de colocar em evidência uma relação genética essencial entre essas duas partes, sem o que nós cairíamos, com nossos comentários sobre o delírio de Schereber, no papel ridículo que descreve Kant na sua célebre comparação na Crítica da razão pura, onde um homem segura uma peneira sob a barba de um bode enquanto outro tenta ordenhá-lo (Freud, 2009 [1911], p. 257).

Não se trata aqui de fazer uma exegese do nascimento do termo metapsicologia em Freud, nem de todos os seus desenvolvimentos, reapresentando as miríades de variações de sentido e referência que esse termo e esse modo de teorização têm recebido. Mas sim tornar claro qual destino a teorização metapsicológica encontrou após Freud, por meio de autores de referência (cf. Assoun, 1993b, 1997, 2000, 2006; Fulgencio, 2003, 2008; Gill, 1976; Green, 1995, 2002; Imbasciati, 2002a, 2002b, 2007, 2010; Klein, 1969; Roudinesco \& Plon, 1997; Simanke, 2009b; Simanke \& Caropreso, 2011). Nesse trajeto focarei principalmente as discussões apresentadas por Fulgencio (2003, 2007b, 2008) e Girard (2010), os quais tratam diretamente da questão da presença e da ausência da teorização metapsicológica em Freud e em Winnicott.

Proponho considerar que há dois sentidos gerais e díspares, ainda que na maioria das vezes misturados, do termo metapsicologia na psicanálise. Por um lado, ele é sinônimo de uma teoria geral do desenvolvimento afetivo que considera, como seu fundamento, as determinações geradas por processos psíquicos inconscientes; por outro lado, corresponde ao nome dado a um conjunto de conceitos auxiliares de natureza especulativa que constitui uma superestrutura teórica substituível, mas cujos referentes jamais poderiam ser encontrados adequadamente na realidade fenomênica. 


\section{Os SENTIDOS DADOS AO TERMO METAPSIGOLOGIA}

Pode-se afirmar que há dois tipos de conceitos, de naturezas diferentes, no corpus teórico da psicanálise elaborada por Freud (cf. Grünbaum, 1996). Em um deles temos conceitos que têm ou podem ter referentes adequados na realidade fenomênica, tais como o de sexualidade infantil, complexo de Édipo, transferência, resistência, recalcamento etc., constituindo um conjunto teórico que prefiro caracterizar como a psicologia dos fatos clínicos desenvolvida por Freud, a qual considera as determinações dos processos inconscientes. ${ }^{2}$ Noutro sentido, temos conceitos que são construções teóricas auxiliares, de valor apenas heurístico, dos quais não podemos encontrar um referente adequado na realidade fenomênica, tais como os de pulsão, libido e de aparelho psíquico. Freud caracterizou-os como parte da superestrutura especulativa [spekulativer Überbau] da psicanálise (Freud, 2009 [1925], p. 80), constituindo um conjunto teórico que creio ser correto caracterizar como a teoria metapsicológica, em um sentido mais estrito da expressão.

Ainda nessa direção, é preciso esclarecer que nem toda teorização é especulativa. Efetivamente, não há conceito que não seja uma abstração; no entanto, há aqueles que têm (ou podem ter) referentes na realidade fenomênica e os que jamais terão. $\mathrm{O}$ conceito de Pégaso é diferente do conceito de cão. Para Freud, os conceitos metapsicológicos (por exemplo, pulsão ou Trieb, libido, aparelho e instâncias psíquicas) são construções auxiliares de valor apenas heurístico, ou seja, são especulativos, como também o são diversos modelos teóricos usados nas ciências duras (por exemplo, o modelo do DNA como uma hélice helicoidal). ${ }^{3}$

Considerando a posição de Freud, que toma a metapsicologia como uma ficção teórica, uma superestrutura especulativa, passível de ser substituída por outras similares de valor heurístico superior, entretanto necessária, podemos então observar que, após Freud, esse tipo de teorização teve diversos destinos. Assoun (2000, 2006), ao analisar os destinos da teorização metapsicológica após Freud, afirma que: 1) autores como Abraham, Ferenczi e Klein, Ferdern e Anna Freud, a revisitaram, modificando, grosso modo, o quadro estabelecido por Freud; 2) autores como Fairbairn, Hartmann, Kohut, Kris, Löwenstein, Fenichel e Bowlby, a retificaram, introduzindo aspectos que não es-

2 Freud (2009 [1912]) diferencia três sentidos para o termo inconsciente, a saber, o descritivo, o dinâmico e o sistêmico. Somente o terceiro poderia ser considerado, stricto sensu, o sentido metapsicológico, dado que supõe sistemas de um aparelho psíquico fictício, sendo os outros dois mais propriamente empírico-descritivos. Uma comparação entre a noção de inconsciente em Freud e em Winnicott poderia explicitar que, do ponto de vista de Winnicott, o inconsciente descoberto por Freud corresponde ao inconsciente reprimido, e que, para além desse inconsciente, haveria de se conceber outro tipo, não redutível ao inconsciente reprimido.

3 Cf. Fulgencio (2001, 2006, 2007a) para uma análise desse aspecto da teoria kantiana da ciência e sua relação com a posição de Freud. 
tavam presentes ou em destaque em Freud; 3) autores como Marty e Aulagnier a teriam usado como um tipo de caixa de ferramentas, que deve se adaptar aos quadros psicopatológicos em foco; 4) autores como Binswanger, Bion e Lacan a teriam redescrito, propondo outro quadro metapsicológico, com mudanças em seus fundamentos; 5) e Winnicott teria se mantido indiferente a ela. Aqui não me ocuparei em analisar cada um desses destinos, descrevendo suas especificidades, mas tomarei dois pontos extremos - a saber, Freud afirmando a sua necessidade, e Winnicott se mantendo indiferente a ela - para esclarecer duas opções metodológicas opostas.

Nesse sentido, note-se, por exemplo, a posição de Lacan. No Seminário I, quando procura explicitar sua metodologia de produção teórica, ele se apoia em Freud para reiterar o uso de certas ficções teóricas, e cita, então, a seguinte passagem da Interpretação dos sonhos:

Afastemos-nos logo da noção de localização anatômica. Fiquemos no terreno psicológico e procuremos apenas nos representar o instrumento que serve às produções psíquicas como uma espécie de microscópio complicado, de aparelho fotográfico etc. O lugar psíquico corresponderá a um ponto desse aparelho onde se forma a imagem. No microscópio e no telescópio, sabe-se que estão aí dois pontos ideais aos quais não corresponde nenhuma parte tangível do aparelho. Parece-me inútil escusar-me pelo que a minha comparação possa ter de imperfeito. Só a emprego para fazer compreender o agenciamento do mecanismo psíquico, decompondo-o e determinando a função de cada uma das suas partes. Não creio que ninguém nunca tenha ainda tentado reconstruir assim o aparelho psíquico. O ensaio não tem risco. Quero dizer que podemos deixar livre curso a nossas hipóteses, desde que preservemos o nosso julgamento crítico, e que não tomemos o andaime pelo próprio prédio (Freud, 2003 [1900], p. 659).

Em seguida, com bom humor, Lacan comenta como pretende ser mais freudiano do que Freud:

Inútil dizer-lhes que, como os conselhos são dados para não serem seguidos, não deixamos desde então de tomar o andaime pelo prédio. Por outro lado, a autorização que Freud nos dá de utilizar relações auxiliares para nos aproximarmos de um fato desconhecido, me incitou a dar provas de certa desenvoltura para construir um esquema (Lacan, 1983, p. 92).

Não parece haver dúvidas quanto à importância que Lacan deu às suas próprias especulações teóricas, especialmente no que se refere ao uso que fez do estruturalismo 
antropológico e linguístico e dos conceitos de outras disciplinas, sempre modificando-os a seu gosto para a construção da sua própria metapsicologia. Com efeito, diversos comentadores de Lacan têm insistido sobre a importância dada a esse tipo de teorização no desenvolvimento da psicanálise (cf. Assoun, 2000; Simanke, 2003).

Contrariamente, Winnicott avalia a metapsicologia como uma ilusão do entendimento:

Estou tentando descobrir por que é que tenho uma suspeita tão profunda com esses termos [metapsicológicos]. Será que é por que eles podem fornecer uma aparência de compreensão onde tal compreensão não existe? Ou será que é por causa de algo dentro de mim? Pode ser, é claro, que sejam as duas coisas (Winnicott, 1990a. Carta para Anna Freud, 18 de março de 1954).

Assoun (2006, p. 67) considera Winnicott como um autor que é indiferente à metapsicologia, colocando mesmo em questão a sua pertinência ao campo da psicanálise. Fulgencio $(2007 \mathrm{c})$, por sua vez, defende que Winnicott rejeitou a metapsicologia como modo de teorização na psicanálise, enquanto que Girard (2010), contrariamente, sustenta que ele refundou a metapsicologia. Procurarei então, retomando os termos específicos dessa discussão, fazer alguns esclarecimentos que, a meu ver, contribuem para mostrar que Winnicott fez ambas as coisas. Considero, no entanto, que não é necessário retomar neste artigo o conjunto de análise e provas documentais que especificam a natureza e a função da metapsicologia para Freud - inserido no seu programa kantiano para construção de uma psicologia científica - bem como a análise do texto de Winnicott que mostra sua rejeição a esse tipo de ficção heurística.

\section{INTEGRAÇÃo DE PERSPEGTIVAS: A METAPSIGOlogia REJEITADA E A REFUNDADA POR WINNICOTT}

Girard considera que Winnicott "proporciona uma fundação factual para a metapsicologia" (2010, p. 305). Para a autora, o conjunto de propostas de Winnicott - tais como a consideração da imaturidade do bebê, da situação inicial de dependência e o desenvolvimento em direção à independência com a introdução do mundo em pequenas doses, do reconhecimento das necessidades do ego (necessidades de ser) como diferente das necessidades do id (instintuais) - fornece elementos factuais que preenchem o que seria um conteúdo especulativo da metapsicologia. No entanto, creio que Girard não faz uma distinção muito clara entre a metapsicologia como superestrutura especulativa e a metapsicologia como teoria do desenvolvimento considerando o inconsciente. 
Nesse sentido, desejo destacar dois pontos específicos, comentados por Girard, para esclarecer o lugar da metapsicologia em Winnicott, mais especificamente para marcar os temas que exigiriam uma análise mais detalhada do que para fazer deles uma análise pormenorizada, a saber,

(1) a questão da existência ou não de uma tópica em Winnicott e

(2) a questão do nascimento da vida psíquica e da distinção entre vida instintual e vida pulsional.

\section{HaVeria Uma tópica EM WinNicott?}

Apesar de Winnicott fazer uso constante dos termos id-ego-superego, classicamente referidos à segunda tópica, cabe perguntar se ele está reiterando a metapsicologia freudiana referindo-se a esses termos como instâncias de um aparelho psíquico fictício. Considero que Winnicott redescreveu o sentido e o referente desses conceitos, jamais considerando-os em seu sentido especulativo. Sendo assim, ao id corresponderiam as pressões instintuais elaboradas imaginativamente (cf. Winnicott, 1983e, 1999b); ao ego, tanto o nome de uma tendência inata para a integração (cf. Winnicott, 1978a) quanto à própria unidade, nos seus diversos graus, do sujeito psicológico (cf. Winnicott 1978a, 1978b, 1983e); e, ao superego, um conjunto de valores e ideais pessoais que orientam, julgam e delimitam as ações, pensamentos e sentimentos do ser humano (1994,b).4

Girard (2006, 2010) está de acordo com a afirmação de que Winnicott reformulou o sentido dado aos conceitos de id- ego-superego, dado que estes são pensados na consideração da radical imaturidade inicial do bebê, na diferenciação entre as necessidades do id como díspares das necessidades do ego, e na recolocação da importância da noção de ser, da continuidade de ser, bem como da importância da sustentação e adaptação real do ambiente na relação de dependência inicial do ambiente. Para ela, Winnicott, ao colocar em evidência esses fatos, reformula a teoria do desenvolvimento psicoafetivo, especificando condições para nos referirmos ao id, ao ego e ao superego, como também às dinâmicas da vida psíquica. Ademais, Winnicott pode descrever aquilo

\footnotetext{
4. Uma análise dedicada a mostrar a diferença entre a maneira como Winnicott e Freud conceberam esses termos deveria ser desenvolvida em mais detalhes, buscando verificar em que medida Winnicott redescreveu o sentido metapsicológico desses conceitos nos dois sentidos que expus acima. Desenvolvo no momento uma pesquisa nessa direção, contando com o apoio do Conselho Nacional de Desenvolvimento de Pesquisa, dedicando-me à análise dos sentidos dados por Freud e Winnicott aos conceitos de inconsciente, id, ego, superego e narcisismo primário. As afirmações acima descritas são um resumo sintético do estado atual de minha pesquisa.
} 
que Freud teria considerado como um dado (os bons cuidados maternos iniciais), modificando a metapsicologia de Freud:

É nesse nível [da compreensão dos cuidados maternos iniciais] que os axiomas, que ele [Winnicott] propõe, parecem-me, simultaneamente, estar operando fora do campo da metapsicologia freudiana e também estar fornecendo uma base para essa metapsicologia [freudiana], levando-o não a rejeitá-la ou substituí-la, mas circunscrevê-la (Girard, 2010, p. 315).

Para Girard, com Winnicott temos um avanço na compreensão da topografia interna da vida psíquica e, nesse sentido, o ponto de vista tópico da metapsicologia teria apenas recebido um conteúdo factual passível de apreensão fenomenológica (cf. Girard, 2010). Creio que é nesse sentido explicitado por Girard que podemos interpretar a afirmação de Winnicott - ao comentar a expressão "eu estou só", distinguindo, por um lado, o indivíduo que se integrou numa unidade, e por outro, o mundo exterior - de que a distinção entre o eu e o mundo exterior corresponde a uma distinção topográfica (cf. Winnicott, 1983a, p. 34,-5), opondo, assim, tanto a personalidade como o mundo externo como dados factuais (e não como instâncias de um fictício aparelho psíquico).

Poderíamos, ainda, nessa direção, questionar se a concepção dos objetos subjetivos e dos objetos e fenômenos transicionais em Winnicott, com a formulação do conceito de espaço potencial (cf. Winnicott, 1975b), bem como sua formulação sobre a vida cultural referindo-se aos fenômenos transicionais (cf. Winnicott, 1975a, 1975b), não corresponderiam a um aprofundamento do ponto de vista tópico, isto é, a proposta de uma tópica especificando três modos de relação com a realidade (o subjetivo, o transicional e objetivo). De minha parte não colocaria objeção alguma em caracterizar tais distinções como uma tópica, desde que esteja claro que essa descrição não corresponde a uma ficção teórica e a uma analogia, como a da figuração analógica de um aparelho para pensar o psiquismo. Não obstante, em meu entender trata-se de uma descrição dos modos de ser e estar no mundo de um ser humano que não existe como uma mônada, mas sim composto por diversos interesses na sua constituição psicoafetiva.

Considero, pois, que não podemos falar de uma tópica metapsicológica em Winnicott da mesma maneira que falamos nas tópicas de Freud, ainda que possamos distinguir uma estrutura não unitária do funcionamento psicoafetivo do ser humano, com dinâmicas e modos de funcionamento do indivíduo que podem ter interesses e objetivos em conflito. 


\section{As NEGESSIDADES DO EGO E O DESENVOLVIMENTO DAS NEGESSIDADES DO ID}

Ao referir-se à questão da emergência da vida psíquica e à teoria freudiana do apoio, ou seja, à compreensão da pulsão nascida como um representante psíquico de uma excitação somática, dando início à constituição dos objetos internos e à realidade psíquica, Girard (2006) considera que Winnicott forneceu explicações mais consistentes e detalhadas sobre aquilo que ocorre nas fases mais primitivas do desenvolvimento, quando há a transformação da vida instintual em vida pulsional, referindo-se aos fatos iniciais que levam em conta a extrema imaturidade do bebê, a situação de dupla dependência e a unidade mãe-bebê dos cuidados maternos (cf. Girard, 2010). A autora faz uma distinção entre a vida instintual e a vida pulsional, considerando que "sem a cobertura do eu dado pela mãe-ambiente, não há, para Winnicott, a possibilidade de uma vida pulsional, há somente uma vida instintual. São as condições do nascimento da vida psíquica e da vida pulsional que estão em questão" (Girad, 2006, p. 25). Creio que o aprofundamento dessa questão exigiria, por um lado, retomar a distinção entre a noção de instinto em Winnicott - isto é, pressões biológicas efetivas que, elaboradas imaginativamente, exigem ação (cf. Winnicott, 199ob) - e a de pulsão em Freud - conceito convencional, ideia abstrata, mito, cujo esforço pedagógico de Freud fornece um conteúdo analógico intuitivo, afirmando-o como um conceito limítrofe entre o somático e o psíquico (dentre a vasta literatura, cf. Armengou, 2009; Assoun, 1997; Fulgencio, 2005; Loparic, 1999b). E, por outro lado, distinguir, como fez Girard, as necessidades do ego e as necessidades do id - as quais tomo como sinônimo de necessidades instintuais - e o desenvolvimento dessas necessidades.

Pode-se afirmar que, para Winnicott, as necessidades do ego dizem respeito, inicialmente, à necessidade de ser que, por sua vez, não é pensada em termos da vida instintual (cf. Winnicott, 1994a). A situação inicial, que Winnicott caracteriza como sendo a relação de dependência absoluta, na qual a mãe-ambiente se adapta às necessidades do bebê, constituindo com ele uma unidade, corresponde à situação na qual o bebê depende da mãe-ambiente sem ter a noção da dependência. Na sua imaturidade inicial, que nada sabe de si ou do ambiente, nem tem a possibilidade de distinguir suas necessidades e muito menos objetos que poderiam atendê-las, o bebê se relaciona com objetos que são, do seu ponto de vista, e não do ponto de vista do observador, ele mesmo, o que leva Winnicott a nomear os objetos com os quais o bebê se "relaciona" como sendo objetos subjetivos. A afirmação de Winnicott de que o ser é condição para que possa existir o fazer (1999b) - sinônimo de relacionar-se com objetos, usá-los, e certamente o fazer que diz respeito à administração da vida instintual nas relações interhumanas - introduz uma perspectiva de compreensão da via psicoafetiva que é distinta da que Freud descobriu com sua descrição da relações de objeto marcadas pela vida 
sexual infantil e, nesse sentido, pelas pulsões. 5 O que aqui afirmamos é que, por um lado, os instintos e o desenvolvimento da vida instintual correspondem a um dos aspectos do processo de amadurecimento do ser humano, ao qual talvez pudéssemos nos referir como as necessidades do id. Enquanto que, por outro lado, as necessidades do ego, ao menos inicialmente, estão referidas à necessidade de ser não redutíveis à vida instintual.

Inicialmente, os instintos são vividos pelo bebê como externos a ele. Conforme Winnicott:

Deve-se ressaltar que ao me referir a satisfazer as necessidades do lactente não estou me referindo à satisfação de instintos. Na área que estou examinando os instintos não estão ainda claramente definidos como internos ao lactente. Os instintos podem ser tão externos como o troar de um trovão ou uma pancada. O ego do lactente está criando força e, como consequência, está a caminho de um estado em que as exigências do id serão sentidas como parte do self, não como ambientais (Winnicott, 1983d, p. 129).

Com efeito, só mais tarde os instintos são integrados ao self e às relações interpessoais, tanto no cenário das relações ainda duais quanto no cenário das relações triádicas, marcadas pelo complexo de Édipo. Aquilo que Freud descobriu e caracterizou como a sexualidade, tanto infantil como adulta, corresponde, para Winnicott, ao que os neuróticos (aqueles que chegaram a se constituírem como pessoas inteiras) vivem nas suas relações interpessoais. Nesse sentido, podemos afirmar que a sexualidade corresponderia a uma determinada maneira, elaborada e mais madura, de viver a vida instintual.

Para Winnicott, os instintos, considerados efetivas pressões biológicas, são, desde o início, elaborados imaginativamente, ou seja, recebem sentidos, sendo registrados, catalogados, diferenciados, organizados, admitindo-se, por assim dizer, coloridos semânticos (cf. Winnicot 1983b, 1983e, 1990a, 1990b, 1999a). A elaboração imaginativa não corresponde a uma representação psíquica da excitação somática, nem é sinônimo de fantasia sexual, o que implicaria uma série de maturidades do indivíduo que não estão presentes no início, mas a uma atividade que estabelece uma semântica para as vivências corporais, que, além de organizar e unificar as vivências instintuais, contribui para que o indivíduo possa preparar-se para a satisfação dessas pressões instintuais

5 Alguns autores (por exemplo, Green, 2011; Loparic, 2001, 2006; Phillips, 1988; Roussillon, 2009) têm afirmado que Winnicott, ao introduzir a questão do ser como fundamento e motor da existência humana, fez uma ruptura epistemológica na ontologia psicanalítica. 
(cf. Winnicott, 199ob). Winnicott considera que, ao longo do processo de amadurecimento, a elaboração imaginativa das funções corporais ocorre em termos de tipos de excitação instintual dominante, por exemplo, a excitação oral do início e a genital da maturidade. A sexualidade, para ele, não seria um dado inicial, um motor do funcionamento da vida psíquica, mas sim uma conquista do processo de amadurecimento, que exigiria, por um lado, a obtenção e a manutenção de uma integração que torna possível ser e, por outro lado, o desenvolvimento da vida instintual elaborada imaginativamente sobre essa aquisição dinâmica básica, integrando essa instintualidade no self e nas relações interpessoais duais, triádicas e múltiplas. A sexualidade humana, tanto a infantil como a adulta, corresponderia a uma conquista do processo de amadurecimento, fundada no desenvolvimento da vida instintual, ou seja, uma determinada maneira de viver a elaboração imaginativa das pressões biológicas, na qual temos um indivíduo integrado reconhecendo e significando as excitações corporais como advindas de si mesmo. Indivíduo esse que pode reconhecer objetos adequados à satisfação de suas excitações, bem como à associação das excitações corporais a fantasias na maturidade, em especial as que envolvem o cenário edípico e genital. ${ }^{\mathbf{6}}$

Ao retomar as descrições de Winnicott sobre as necessidades de ser e sobre o desenvolvimento da vida instintual tive como objetivo: 1) indicar meu acordo com Girard sobre a afirmação de que Winnicott redescreveu as fases iniciais do processo de desenvolvimento psicoafetivo, refundando a teoria psicanalítica sobre esse processo, pensado, então, em termos da situação inicial da dupla dependência, da extrema imaturidade do bebê e da diferença entre as necessidades do ego e as do id; 2) apresentar uma compreensão sobre o desenvolvimento da vida instintual e sua relação com a conquista da sexualidade, sem que fosse necessário considerar que haveria uma passagem que vai da vida instintual para a vida pulsional, o que reiteraria minha afirmação de que Winnicott rejeitou o conceito de pulsão, substituindo-o pelo de necessidade e de elaboração imaginativa das funções corporais.

\section{Conceitos abstratos E conceitos espegulativos em Winnigott}

Tendo em mente que as propostas de Winnicott redescrevem a teoria do desenvolvimento do ponto de vista da psicanálise, reitero, agora, os aspectos da metapsicologia psicanalítica que foram rejeitados por Winnicott, a saber:

6 Alguns autores, tais como, por exemplo, Girard (2006), Green (2005a), Loparic (2007) e Phillips (1988), têm comentado o lugar da sexualidade na obra de Winnicott, diferenciando-a da instintualidade. 
(1) sua concepção sobre o que são os instintos, isto é, pressões biológicas efetivas que exigem ação, e não um tipo de mitologia;

(2) sua proposta sobre a estrutura de organização da vida psicoafetiva sem o uso da ficção teórica de aparelho psíquico dividido em instâncias, analogamente a um microscópio ou telescópio;

(3) sua ideia de que há variações de intensidades afetivas, sem a suposição de uma energia psíquica análoga às energias tal como a física as postula;

(4) sua recusa da pulsão de morte;

(5) sua crítica à noção de inveja inata.

Caberia, ainda nessa direção, perguntar se as noções de ser, continuidade de ser, elemento feminino e masculino puros, solidão essencial, tendência inata à integração, núcleo sagrado do self e elaboração imaginativa das funções corporais não seriam também especulações e, nesse sentido, estariam apenas substituindo a superestrutura especulativa freudiana por uma outra de mesmo tipo epistemológico, tal como propuseram Lacan e Bion. Essa parece ser a posição de Girard, quando afirma que Winnicott "poderia também ter proposto uma formulação abstrata (tal como Bion ou Lacan), mas, talvez, esse não correspondesse a seu estilo" (Girard, 2006, p. 52). Ou ainda quando diz:

Finalmente, recolocado no contexto geral de obras de Winnicott, esta proposição aparece como uma grande construção teórica especulativa que não envolve nem a rejeição dos conceitos básicos da metapsicologia, nem a sua diluição ou desintegração, mas abre outro campo: a do ser (Girard, 2010, p. 317).

Respeitadas as diferenças entre conceitos que podem e não podem ter referentes adequados na realidade fenomênica, creio que aqueles formulados por Winnicott não poderiam ser considerados, stricto sensu, especulações do mesmo tipo que as propostas por Freud. A noção de ser não corresponde a um mito ou a uma ficção teórica, não é nem mesmo uma analogia, mas uma experiência reconhecível tanto pela sua presença (aqueles pacientes que conseguiram conquistar um lugar no qual podem ser e continuar sendo) quanto pela sua ausência (aqueles que lutam para chegar a ser, seja porque jamais encontraram as condições ambientais para isso, seja porque se constituíram como um falso-self patológico). No caso em que Winnicott se refere à solidão essencial, estado de não ser de onde vem o ser (cf. Winnicott, 199ob, p. 153-6), pode-se argumentar que também não se trata de algo que possa ter realidade fenomênica, pois só o ser pode tê-la do ponto de vista filosófico e epistemológico. No entanto, não se trata de uma especulação ou mito, mas de um existente que pode vir à tona justamente nos casos em que o indivíduo não pode advir, nos casos em que ele foi invadido naquilo 
que Winnicott caracterizou como sendo o núcleo sagrado do self (cf. Winnicott, 1983c, p. 170). Nesses casos a falta de ser e as invasões ou aniquilações do ser são reconhecidos como fatos que têm referentes na realidade fenomênica e, portanto, é possível fornecer referentes adequados (factuais) a esses conceitos, ainda que eles não possam ser objetiváveis tal como são os conceitos de transferência, resistência, complexo de Édipo, sexualidade infantil etc.

Certamente esses conceitos não são objetiváveis, tais como o de cão ou de transferência, no entanto, ainda que abstratos, não são especulativos como os conceitos de pégasu e de aparelho psíquico, que jamais poderão ter um referente adequado na realidade fenomênica. $O$ fato de que algo não possa ser objetivável não significa que seja uma especulação. Por exemplo, o elétron, como onda ou como partícula, também foi considerado, na física, de difícil objetividade e nem por isso foi tomado como uma especulação. Por outro lado, sabemos que o mito de Totem e tabu, bem como as pulsões, dentre outros conceitos desse tipo, jamais terão referentes que lhes correspondam adequadamente. Nesse sentido, considero que esses conceitos de Winnicott - a saber, as noções de ser, continuidade de ser, elemento feminino puro, solidão essencial, tendência inata à integração, núcleo sagrado do self, elaboração imaginativa das funções corporais não seriam construções auxiliares que fariam parte de uma superestrutura especulativa da psicanálise, mas conceitos que têm algum referente possível na realidade fenomênica, ainda que não objetiváveis. São conceitos que tornam possível descrever os aspectos factuais que estão na base do processo de desenvolvimento e funcionamento da vida psicoafetiva.

\section{ConsideraÇões Finais}

Creio que a consideração desses dois sentidos para o termo metapsicologia - como teoria psicanalítica sobre o desenvolvimento psicoafetivo e como conjunto de conceitos especulativos, de valor necessariamente apenas heurístico - pode marcar uma linha divisória, metodológica e epistemológica, estabelecendo duas perspectivas diferentes para o uso e o desenvolvimento da teoria e da prática psicanalítica: uma primeira que procura expandir, reformular e mesmo substituir a teorização metapsicológica de Freud por outra também de validade apenas heurística; e uma segunda que, rejeitando esse modo de teorização, procura formular teorias e conceitos que teriam referentes empíricos na realidade factual. Nesse sentido, para fazer uma síntese da perspectiva aqui proposta, talvez seja correto afirmar que, no que se refere a Freud, Winnicott substituiu uma metapsicologia especulativa por uma metapsicologia descritiva, tal como já afirmou Andrews: 
Pode haVer UMA GiÊNGiA PSIGANALÍtica SEM UMA METAPSigologia ESPEGUlativa?

[Winnicott] possibilita, no meu entender, mais do que outros, que os referentes abstratos se encarnem na individualidade de cada condição humana e cultural, precisamente por favorecer a possibilidade de configurar uma Metapsicologia do ser em detrimento de uma Metapsicologia da pulsão (Andrews, 2011, p. 590).

Em termos mais gerais, tendo em mente o desenvolvimento da psicanálise após Freud e os diversos destinos dados à teorização metapsicológica, é possível colocar a seguinte questão, que poderia ser dirigida a todos os representantes e defensores de qualquer um dos grandes sistemas teóricos atuais: o que restaria da teoria e da prática psicanalítica caso toda a metapsicologia especulativa fosse excluída, e toda a teorização ou procura de descrição dos processos psíquicos, e dos processos e tratamentos clínicos psicanalíticos, tivesse que ser feita ou refeita sem o uso dessas especulações? Como exemplo desse modo de proceder, podemos retomar a conhecida rejeição que Winnicott faz do conceito de pulsão de morte, e sua sugestão em carta a Hans Thorner:

Gostaria de dizer, porém, que as coisas ficam confusas, na Sociedade, quando vários termos são usados como se fossem plenamente aceitos. Tenho certeza de que você sabe exatamente o que tem em mente quando diz: "partes perigosas (...) derivadas do instinto de morte [death instinct] devem ser expulsas", eu mesmo não sei o que você quer dizer, e pelo menos metade da Sociedade deve sentir que você está dizendo "instinto de morte", em vez de usar as palavras "agressividade" e "ódio". Você talvez ache que isso não tem importância, e não tem mesmo, no contexto de seu ensaio, mas seria realmente muito útil para a Sociedade se conseguíssemos descobrir uma linguagem comum. Qualquer hora dessas, quando você não tiver nada para fazer, que tal reescrever aquela frase sem usar as palavras "instinto de morte”, só por minha causa? (Winnicott, 1990a, p. 134)

Essa proposta, aplicável a todos os sistemas teóricos da psicanálise, como também a outros sistemas teóricos da psicologia, a saber, a de retirar os termos e conceitos especulativos e procurar descrever os fatos sem o seu uso - proposta essa que pode ao menos ser experimentada, para ver onde chegaríamos -, poderá explicitar com mais precisão a necessidade ou não da teorização metapsicológica especulativa na psicanálise, levando em conta o valor heurístico das teorias no que se refere à formulação, descrição e resolução de efetivos problemas empíricos (clínicos) da ciência psicanalítica.

Essa perspectiva de construção de uma psicanálise como uma ciência que possa ser edificada sem a utilização de construções auxiliares especulativas, sem o uso de metáforas e analogias com sistemas maquínicos ou naturais, ou ainda, sem a procura da redutibilidade dos fenômenos humanos a fórmulas e estruturas lógico-formais, 
parece, por um lado, contribuir para o desenvolvimento da avaliação da cientificidade da psicanálise e, por outro, também parece contribuir para a compreensão das ressonâncias significativas, já reconhecidas, entre a obra de Winnicott e os fundamentos propostos pela fenomenologia, a psicologia existencialista e a Daseinanalyse, para a edificação de uma psicologia científica.

Nessa direção, pode-se notar que Ellenberger considerou que o obra de Ricoeur e a proposta de Binswanger foram tentativas tanto para superar os impasses que a psicanálise encontrava para se afirmar como uma ciência quanto para integrar os fundamentos e as propostas que sustentariam a construção de uma psicologia científica do ponto de vista da fenomenologia e da analítica existencial (cf. Ellenberger 1958, 1961, 1966). Com efeito, pode-se especular, já que não temos mais acesso ao que havia na biblioteca de Winnicott, que ele teria tido acesso a esses textos, acima citados, de Ellenberger. Na mesma perspectiva, Loparic (2002), ao avaliar como inadequada a solução dada por Binswanger, tem defendido a proximidade entre a perspectiva psicanalítica desenvolvida por Winnicott e a analítica existencial de Heidegger (cf. Loparic 1999a, 2001, 2012).

Essas observações correspondem apenas a uma indicação do imenso campo de pesquisas a serem desenvolvidas, sejam as que se desenvolvem no campo da filosofia da psicanálise, sejam as que se desenrolam no campo do desenvolvimento da ciência psicanalítica ela mesma, enquanto prática de resolução de problemas empíricos que se dá em um momento pré-paradigmático e cujo desenvolvimento implicaria num sistema mais maduro, um paradigma de maior poder heurístico que tanto integraria como excluiria determinadas perspectivas hoje em confronto.๑

Agradecimentos. Este texto foi redigido a partir de conferência proferida na mesa de abertura do "IV Congresso Internacional de Filosofia da Psicanálise. Filosofia da Psicanálise Hoje” (Salvador, Brasil, novembro de 2011).

\section{Leopoldo Fulgencio}

Programa de Pós-Graduação em Psicologia, Pontifícia Universidade Católica de Campinas, Brasil.

leopoldo.fulgencio@gmail.com

\section{Can there be a psychoanalytical science without a metaphysical meta-psychology?}




\begin{abstract}
The purpose of this article is to elucidate two basic meanings given to the term "meta-psychology" in the history of psychoanalysis: as a theory about the psycho-affective development of the human being which takes into account unconscious determinations, and as a group of supporting concepts which serve as a speculative theoretical superstructure of psychoanalysis. Secondly, this article will show why Winnicott rejected and refunded the meta-psychological psychoanalytical theory. With this type of analysis, it is possible to explain how Winnicott uses abstract concepts (such as "need of being", "inborn tendency towards integration", "pure feminine element", "essential loneliness", among others) but not speculative concepts, seeing that abstract concepts may have appropriate referents in the phenomenal reality and speculative concepts may not. This type of difference is also used to examine the issue of the place and the need of a meta-psychological theorization in the development of psychoanalysis, offering the possibility of constructing a psychoanalytical theory as a science which needs no speculative supporting constructions as suggested by Freud.
\end{abstract}

KEYwords $\bullet$ Psychoanalysis. Science. Meta-psychology. Speculation. Description.

\title{
REFERÊNGIAS BIBLIOGRÁFIGAS
}

Andrews, J. C. El concepto de pulsión en Winnicott. In: . El oficio en lo invisible. Los derechos del paciente en la prática psicoanalítica. Providencia: Ocho Libros, 2011. p. 587-94.

Armengou, F. G.-C. The death drive: conceptual analysis and relevance in the Spanish psychoanalytic community. The International Journal of Psychoanalysis, 90, 2, p. 263-89, 2009.

Assoun, P.-L. Introduction à l'épistemologie freudienne. Paris: PUF, 1981. Freud et les sciences sociales. Paris: Armand Colin, 1993a. . Introduction à la métapsychologie freudienne. Paris: PUF, 1993b. . Psychanalyse. Paris: PUF, 1997. La métapsychologie. Paris: PUF, 2000.

Le symptôme humain: Winnicott a-métapsychologue. In: La nature humaine à l'épreuve de Winnicott. Paris: PUF, 2006. p. 61-78.

BERNARDI, R. The role of paradigmatic determinants in psychoanalytic understanding. International Journal of Psychoanalysis, 70, p. 341-55, 1989.

. The need for true controversies in psychoanalysis: the debates on Melanie Klein and Jacques Lacan in the Río de la Plata. The International Journal of Psychoanalysis, 83, 4, p. 851-73, 2002.

Breger, L. (Ed.). Clinical-cognitive psychology: models and integrations. Englewood Cliffs: Prentice Hall, 1969.

Ellenberger, H. F. Introducción clínica a la fenomenologia psiquiátrica y al análisis existencial. In: May, R.; Angel, E. \& Ellenberger, H. F. Existencia. Nueva dimensión en psiquiatría y psicologia. Madrid: Editorial Gredos, 1958. p. 123-60.

. Existentialisme et psychiatrie. In:___. Médecines de l'âme. Essais d'histoire de la folie et des guérisons psychiques. Mesnil-sur-l'Estrée: Fayard, 1961.p. 391-4,16.

. Herméneutique et psychanalyse. In:__. Médecines de l'âme. Essais d'histoire de la folie et des guérisons psychiques. Mesnil-sur-l'Estrée: Fayard, 1966. p. 417-4,28.

FÉdida, P. Préface. Cliniques Méditerranéennes, 41-42, p. 5-8, 1994.

Freud, S. L'intrepretation du rêve. In: __. Oeuvres complètes de Freud. Paris: PUF, 2003 [1900], v. 4. Nouvelles suite des leçons d'introdution à la psychanalyse. In: Paris: PUF, 2004, [1933].v. 19, p. 83-268. . Oeuvres complètes de Freud. 
Freud, S. Remarques psychanalytiques sur un cas de paranoïa (Dementia paranoides) décrit sous forme autobiografique. In: Oeuvres complètes de Freud. Paris: PUF, 2009 [1911]. v. 10, p. 225-304. . Note sur l'inconscient en psychanalyse. In: . Oeuvres complètes de Freud. Paris: PUF, 2009 [1912]. v. 11, p. 169-80.

Autoprésentation. In: . Oeuvres complètes de Freud. Paris: PUF, 2009 [1925]. v. 17, p. 51- 122. L'analyse finie et l'analyse infinie. In: . Oeuvres complètes de Freud. Paris: PUF, 2009 [1937].v. 17 , p. 13-55.

Fulgencio, L. Comentários críticos das referências textuais de Freud a Kant. Psicologia USP, 12, 1, p. 4988, 2001.

. As especulações metapsicológicas de Freud. Revista de Filosofia e Psicanálise Natureza Humana , 5, 1, p. $127-64,2003$

. Freud's metapsychological especulations. International Journal of Psychoanalysis, 86, 1, p. 99-123, 2005 .

. O lugar da psicologia empírica no sistema de Kant. Kant e-Prints, série 2, 1, 1, p. 89-118, 2006. Disponível em: <ftp://ftp.cle.unicamp.br/pub/kant-e-prints/Psicologia\%2oempirica\%2,oem\%20 Kant.pdf $>$. Acesso em: o9 set. 2013.

O kantismo de Freud. Mente, Cérebro \& Filosofia, 3, p. 64-74, 2007 a.

. Paradigmas na história da psicanálise. Revista de Filosofia e Psicanálise Natureza Humana, 9, 1, p.

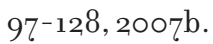

. Winnicott's rejection of the basic concepts of Freud's metapsychology. The International Journal of Psychoanalysis, 88, 2, p. 443-61, 2007c.

. O método especulativo em Freud. São Paulo: EDUC, 2008.

Fulgencio, L. \& Simanke, R. T. Freud na filosofia brasileira. São Paulo: Escuta, 2005.

GiLL, M. M. Metapsychology is not psychology. Psychological Issues, 9, 4, Monograph 36, p. 71-105, 1976.

Girard, M. L'accueil en pratique institutionnelle. Immaturité, schizophrénies et bruissements du monde. Nimes: Champ Social Éditions, 2006.

.Winnicott's foundation for the basic concepts of Freud's metapsychology? The International Journal of Psychoanalysis, 91, 2, p. 305-24, 2010.

Green, A. Propédeutique. La métapsychologie revisitée. Seyssel: Champ Vallon, 1995. Idées directrices pour une psychanalyse contemporaine. Paris: PUF, 2002.

.Winnicott at the start of the third millennium. In: CaLDweld, L. (Ed.). Sex and sexuality: Winnicottian perspectives. London: Karnac Books, 2005a. p. 11-31. (Winnicott Studies Monograph Series).

Winnicott en transition, entre Freud et Melanie Klein. In: Jouer avec Winnicott. Paris: PUF, $2005^{b} \cdot \mathrm{p} \cdot 4^{3-66 .}$

. Origines et vicissitudes de l'être dans l'oeuvre de Winnicott. Revue Française de Psychanalyse, 4, 75, p. 1151-70, 2011.

Grünbaum, A. La psychanalyse à l'épreuve. Paris: L'éclat, 1993. . Les fondements de la psychanalyse. Une critique philosophique. Paris: PUF, 1996.

Im Basciati, A. An explanatory theory for psychoanalysis. The International Journal of Psychoanalysis, 11, 3 , p. $173-83,2002 a$.

.A psychoanalyst's reflections on rereading a cognitivist: toward an explanatory theory of relationship. Psychoanalytic Review, 89, 5, p. 595-63o, 2002b.

. Psychanalyse et neurosciences: pour une nouvelle metapsychologie. Revue Française de Psychanalyse, 71,2, p. 455-77, 2007 .

. Towards new metapsychologies. Psychoanalytic Review, 97, 1, p. 44-61, 2010.

KLein, G. S. Freud's two theories of sexuality. In: Breger, L. (Ed.). Clinical-cognitive psychology: models and integrations. Englewood Cliffs, New Jersey: Prentice Hall, 1969. p. 136-81. 
Pode haVer UMA GiÊNGiA PSicANALÍtica SEM UMA METAPSigologia ESPEGUlativa?

Kunn, T. S. A estrutura das revoluções científicas. São Paulo: Perspectiva, 1975. A tensão essencial. Lisboa: Edições 7๐, 1977.

O caminho desde a estrutura. Ensaios filosóficos, 1970-1993, com uma entrevista autobiográfica. São Paulo: Editora Unesp, 2006.

Lacan, J. O seminário. Livro 1. Os escritos técnicos de Freud. Rio de Janeiro: Zahar, 1983.

Loparic, Z. Heidegger and Winnicott. Revista de Filosofia e Psicanálise Natureza Humana, 1, 1, p. 104-35, 1999a.

. O conceito de Trieb na filosofia e na psicanálise. In: Machado, J. A. T. (Ed.). Filosofia e psicanálise: um diálogo. Porto Alegre: EDIPCRS, 1999b. p. 97-157.

Esboço do paradigma winnicottiano. Cadernos de História e Filosofia da Ciência, 11, 2, p. 7-58, 2001. Binswanger, leitor de Heidegger: um equívoco produtivo? Revista de Filosofia e Psicanálise Natureza Humana, 4, 2, 2002.

De Freud a Winnicott: aspectos de uma mudança paradigmática. Revista de Filosofia e Psicanálise Natureza Humana, 8 (Especial 1), p. 21-47, 2006.

Elementos da teoria winnicottiana da sexualidade. Revista de Filosofia e Psicanálise Natureza Huma$n a, 7,2$, p. 311-58, 2007.

From Freud to Winnicott: aspects of a paradigm change. In: Aвram, J. (Ed.). Donald Winnicott today. London/New York: Routledge, 2012. p. 113-56.

Mezan, R. Existem paradigmas na psicanálise? Percurso, 4, p. 43-533, 1990.

. Sobre a epistemologia da psicanálise. In: . Interfaces da psicanálise. São Paulo: Companhia das Letras, 2002. p. 436-519.

. Paradigmas em psicanálise. Revista de Filosofia e Psicanálsie Natureza Humana, 8 (Especial 1), p. 4962, 2006

Monzani, L. R. O movimento de um pensamento. Campinas: Edunicamp, 1989.

Peirge, C. S. A ética da terminologia. In:___. Semiótica. São Paulo: Perspectiva, 1997. p. 39-433.

Phillips, A. Winnicott. London: Fontana Press, 1988.

Beijo, cócegas e tédio. O inexplorado da vida à luz da psicanálise. São Paulo: Companhia das Letras, 1996.

Ricoeur, P. De l'interpretation. Essai sur Freud. Paris: Seuil, 1965.

Roudinesco, E. \& Plon, M. Dictionnaire de la psychanalyse. Paris: Fayard, 1997.

Roussillon, R. Transitionnel et réflexivité. Les Lettres de la Sociétéde Psychanalyse Freudiene. Winnicott, un psychanalyste dans notre temps, 21, p. 123-4,0, 2009.

Simanke, R. T. Metapsicologia lacaniana: os anos de formação. São Paulo/Curitiba: Discurso Editorial/Editora UFPR, 2003.

. A psicanálise freudiana e a dualidade entre ciências naturais e ciências humanas. Scientix Studia, 7, 2, p. 221-35, 2009a.

. Realismo e anti-realismo na interpretação da metapsicologia freudiana. Revista de Filosofia e Psicanálise Natureza Humana, 11, 2, p. 97-152, 2009b.

. O que a filosofia da psicanálise é e o que ela não é. ETD: Educação Temática Digital, 11, p. 189-214, 2010.

Simanke, R. T. \& Caropreso, F. A metáfora psicológica de Sigmund Freud: neurologia, psicologia e metapsicologia na fundamentação da psicanálise. Scientiæ Studia, 9, 1, p. 51-78, 2011.

Winnicotт, D. W. A localização da experiência cultural. In: O brincar e a realidade. Rio de Janeiro: Imago, 1975a. p. 133-43.

O lugar em que vivemos. In: O brincar e a realidade. Rio de Janeiro: Imago, 1975b. p. 145-52. Formas clínicas da transferência. In: . Da pediatria à psicanálise. Rio de Janeiro: Francisco Alves, 1978a. p. 393-8. 
Winnicott, D. W. A preocupação materna primária. In: Da pediatria à psicanálise. Rio de Janeiro: Francisco Alves, 1978b. p. 399-4,05.

. A capacidade para estar só. In: . O ambiente e os processos de maturação. Porto Alegre: Artmed, 1983a. p. 31-7.

Os objetivos do tratamento psicanalítico. In: O ambiente e os processos de maturação. Porto Alegre: Artmed, 1983b. p. 152-5.

. Comunicação e falta de comunicação levando ao estudo de certos opostos. In: Oambiente es processos de maturação. Porto Alegre: Artes Médicas, 1983c. p. 163-74.

. Distorção do ego em termos de falso e verdadeiro self. In: Oambiente e os processos de maturação. Porto Alegre: Artes Médicas,1983d.p. 128-39.

. A integração do ego no desenvolvimento da criança In: . O ambiente e os processos de maturação. Porto Alegre: Artmed, 1983e. p. 55-61.

. O gesto espontâneo. São Paulo: Martins Fontes, 1990a.

Natureza humana. Rio de Janeiro: Imago, 199ob.

Os elementos masculinos e femininos cindidos encontrados em homens e mulheres In: $. E x-$ plorações psicanalíticas. Porto Alegre: Artmed, 1994a. p. 134-44.

. Comentários sobre "On the concept of the superego" de Joseph Sandler. In: Explorações psicanalíticas. Porto Alegre: Artes Médicas, 1994b. p. 353-58.

Crescimento e desenvolvimento na fase imatura In: A família e o desenvolvimento individual. São Paulo: Martins Fontes, 1999a. p. 29-41.

. O conceito de indivíduo saudável. In: .Tudo começa em casa. São Paulo: Martins Fontes, 1999b. p. 3-22. 